\title{
A CONSTRUÇÃO DA VERDADE BOLSONARISTA
}

\author{
Allan Santos ${ }^{1}$
}

\section{Resumo:}

Em um contexto marcado pela crise da verdade, investigamos empiricamente como o bolsonarismo se apropria dos espaços digitais para a construção dos seus enunciados. Primeiramente, propomos uma revisão teórica que toma a mobilização discursiva do ressentimento decorrente do "poder masculino branco afrontado" como chave de leitura para a compreensão do regime de verdade contemporâneo marcado pela aliança entre o neoliberalismo e o neoconservadorismo. Em seguida, monitoramos as postagens de Jair Bolsonaro em sua página oficial no Facebook por 17 semanas, estabelecendo seis sentidos discursivos predominantes: ataques à imprensa, às instâncias independentes de poder e aos organismos de fomento à ciência, em oposição a um constante apelo ao nacionalismo, ao militarismo e à religiosidade. Metodologicamente, investimos na Análise de Discurso Crítica (FAIRCLOUGH, 1985; WODAK, 2011) para investigar como o discurso bolsonarista constrói a sua verdade por meio das redes sociais de Internet.

Palavras-chave: bolsonarismo; crise da verdade; neoliberalismo; neoconservadorismo; Internet.

\begin{abstract}
:
In a context marked by the crisis of the truth, we investigate empirically how the bolsonarismo appropriates the digital spaces for the construction of its enunciations. First, we propose a theoretical review that takes the discursive mobilization of the resentment arising from the "threatened white male power" as a key for the understanding of the contemporary regime of truth marked by the alliance between neoliberalism and neoconservatism. Then, we monitored Jair Bolsonaro's posts on his official Facebook page for 17 weeks, establishing six predominant discursive meanings: attacks on the press, on independent institutions of power and on science-promoting bodies, as opposed to a constant appeal to nationalism, militarism and religiosity. Methodologically, we invested in the Critical Discourse Analysis (FAIRCLOUGH, 1985; WODAK, 2011) to investigate how the bolsonarist discourse builds its truth through social Internet networks.
\end{abstract}

keywords: bolsonarismo; crisis of the truth; neoliberalism; neoconservatism; Internet.

\section{Introdução}

Ainda no século XIX, Nietzsche (1844-1900) já questionava a relação entre a verdade reconhecida socialmente e a mentira, alertando para um acordo social que girava em torno de uma "vontade de verdade", ou seja, o desejo de encontrar uma verdade eterna e imutável cuja função política era a normatização da vida e a redução da potência do pensamento.

\footnotetext{
${ }^{1}$ Doutorando e mestre em Comunicação e Cultura da Escola de Comunicação da Universidade Federal do Rio de Janeiro (ECO-UFRJ), assim como pesquisador integrante do Núcleo de Estudos em Comunicação, História e Saúde (Nechs - Fiocruz/UFRJ). E-mail: allansantos29ny@gmail.com
} 
Mais recentemente, Foucault (1926-1984) dedicou parte considerável de sua investigação filosófica em busca da compreensão dos processos pelos quais a relação discursos-práticas-instituições se constitui em dispositivos de poder-saber que permitem legislar sobre o verdadeiro e o falso. Nas palavras do filósofo francês:

\begin{abstract}
A verdade é deste mundo; ela é produzida nele graças a múltiplas coerções e nele produz efeitos regulamentados de poder. Cada sociedade tem seu regime de verdade, sua "política geral" de verdade: isto é, os mecanismos e as instâncias que permitem distinguir os enunciados verdadeiros dos falsos, a maneira como se sanciona uns e outros; as técnicas e os procedimentos que são valorizados para a obtenção da verdade; o estatuto daqueles que têm o encargo de dizer o que funciona como verdadeiro (FOUCAULT, 2007, p. 12)
\end{abstract}

Desta forma, na modernidade, a verdade foi alçada à condição de pilar do desenvolvimento social e ético e em seu entorno foram construídos políticas e métodos para se alcançar e reconhecer o verdadeiro em vários campos da vida social. No entanto, a mitologia em torno da véritas - fundamentada pelos critérios da realidade, objetividade e imparcialidade - vem sendo continuamente descontruída na contemporaneidade, distanciando as narrativas informacionais e políticas do factual em direção ao emocional e ao reforço de crenças pessoais e coletivas.

No que tange ao contexto brasileiro contemporâneo, Moretto e Ortellado (2018) com o apoio de cientistas sociais e da computação da Universidade de São Paulo (USP) - analisaram as opiniões e os comportamentos dos usuários brasileiros do Facebook que interagem com páginas políticas na plataforma digital mais usada no país. Ao rastrearem as interações com páginas de atores políticos, movimentos sociais e organização de defesa de direitos, os pesquisadores desenvolveram um mapa de como a opinião pública no país mudou entre 2013 e 2016 no que tange à verdade, revelando um "retrato chocante da polarização política em ação", ou seja, a disseminação de múltiplas verdades sobre o mesmo fato de acordo com as experiências e testemunhos individuais e coletivos.

Segundo Moretto e Ortellado (2018), em 2013, os usuários brasileiros do Facebook com interesses políticos podiam ser categorizados em seis comunidades distintas: 1) políticos e partidos conservadores; 2 ) políticos e partidos de esquerda; 3) grupos anticrime de linha dura; 4) campanhas anticorrupção; 5) movimentos sociais progressistas; 6) direitos humanos e ambientalismo. Além disso, essas comunidades podiam ser perfeitamente distribuídas em dois eixos: a) horizontalmente (da esquerda política para a direita); b) verticalmente (de grupos políticos para participantes de organizações da sociedade civil). A pesquisa evidencia 
que, embora houvesse uma clara diferença entre o comportamento online das pessoas que seguiam os políticos de esquerda e de direita no Brasil, a distância entre os movimentos sociais não era tão grande (havendo sobreposições, por exemplo, entre as comunidades 4 , 5 e 6).

O quadro mudou drasticamente após as Jornadas de Junho de 2013, tendo os grupos começado a se dividir mais acentuadamente entre a esquerda e a direita, enquanto as outras categorias desmoronaram. No final de 2013, os cidadãos da direita política se uniram na questão da corrupção. Aqueles associados ideologicamente à esquerda se agregaram em torno dos programas sociais e serviços públicos, separando os dois grupos política e socialmente. Finalmente, entre 2014 e 2016, as diferenças se tornaram extremamente polarizadas: os usuários do Facebook que compreendiam seis comunidades de interesse e opiniões visivelmente distintas foram separados em apenas dois grupos com pouquíssima sobreposição: progressistas e conservadores. Esse movimento de polarização política passou a ser ainda mais acentuado com a deposição da ex-presidente Dilma em 31 de agosto de 2016.

Focando especificamente na "batalha do impeachment no Facebook", Moretto e Ortellado (2016) capturaram todas as matérias dos quatro dias que precederam a votação do processo na Câmara dos Deputados em 17 de abril de 2016 (reunindo um banco de dados de 8000 artigos jornalísticos que geraram mais de seis milhões de compartilhamentos). Dentre as 100 mais compartilhadas, $80 \%$ ilustravam ou a narrativa da campanha \#NãoVaiTerGolpe! ${ }^{2}$ ou da campanha \#ForaDilma! ${ }^{3}$, o que sugere que as discussões políticas no Facebook foram tomadas por uma dinâmica na qual, de maneira organizada ou espontânea, militantes e aderentes dos dois lados reproduziram mecanicamente a dinâmica polarizada do debate, reforçando as mesmas ideias e deixando sem espaço o discurso político independente. As narrativas com vontade de verdade dos dois lados tinham poucos argumentos centrais, sendo a força persuasiva proveniente da reprodução sistemática de matérias aparentemente diferentes, mas que ilustravam o mesmo ponto de vista, convertendo algumas timelines das redes sociais de Internet em grandes fluxos de propaganda. A pesquisa ainda destaca que o alto grau de compartilhamento desses conteúdos se deve à mobilização das manchetes pelas

\footnotetext{
${ }^{2} \mathrm{Na}$ campanha do \#NãoVaiTerGolpe! duas linhas argumentativas predominaram: uma que defendia que impeachment sem crime de responsabilidade é golpe e outra que argumenta que a oposição, tomada por escândalos de corrupção, não pode condenar o PT (MORETTO, ORTELLADO, 2016).

${ }^{3} \mathrm{Na}$ campanha do \#ForaDilma, três linhas argumentativas se destacaram: a corrupção gerada pelo PT é enorme e intolerável, os defensores do governo são desordeiros perigosos e o PT é um partido autoritário que desrespeita as instituições e é ele, afinal, quem está preparando um golpe (MORETTO, ORTELLADO, 2016).
} 
estratégias discursivas emocionalmente polarizadas das campanhas em torno do processo de impeachment e por uma ampla parcela dos usuários das redes sociais empenhada em difundir as verdades às quais aderem. Como explicam os pesquisadores brasileiros:

\footnotetext{
O efeito do medo de um golpe de estado produzido pela campanha \#NãoVaiTerGolpe! somado ao efeito da indignação contra a corrupção generalizada produzido pela campanha \#ForaDilma! parece ter gerado comportamentos beligerantes permanentes que inundaram a rede social com as mesmas mensagens até o ponto em que quase nada mais consegue ser percebido (MORETTO \& ORTELLADO, 2016).
}

Ao construírem fronteiras simbólicas que demarcaram a existência de múltiplas verdades sobre os mesmos fatos entre um "nós” em diferenciação a um "eles" durante as mobilizações a favor do impeachment, o discurso bolsonarista teve a sua parcela de contribuição no processo de polarização do espectro político brasileiro entre progressistas e conservadores. Se pensarmos a partir do argumento proposto por Dvir-Gvirsman (2017), ao aumentarem a acessibilidade do self-político e reforçarem a consistência de si dos bolsonaristas, os conteúdos digitais em questão tendem a intensificar o extremismo ideológico e a intolerância política por meio de uma espiral de reforço de verdades pessoais. Tendo em vista este cenário de polarização político-ideológica, aventamos que o bolsonarismo se apropriou de elementos da linguagem da memética contemporânea - a lacração, o antagonismo às diferenças e a trollagem - para potencializar, durante o impeachment, a estratégia de ação comunicacional “baseada na confrontação, na coragem e na ousadia” (ROTHBARD, 2015) que se constituiu como o modus operandi do fazer ativismo político digital contemporâneo que dissemina múltiplas verdades nos circuitos midiáticos amplificados.

Um outro problema se apresenta na proliferação discursiva de múltiplas verdades na contemporaneidade digital, segundo Oliveira (2000, p. 86-87), o “desmoronamento dos cânones iluministas" tem promovido um deslocamento epistemológico do "observador cartesiano incorpóreo" para a “corporificação do sujeito do conhecimento”. Há na contemporaneidade uma hipervalorização dos testemunhos e das vivências enquanto radicalização de um regime epistemológico que toma a experiência e a crença como vias privilegiadas para a produção do conhecimento. Neste contexto, a testemunha que experimenta a realidade com o próprio corpo é alçada ao posto de maior autoridade para narrar os fatos: "uma autoridade que, em última instância, repousa na dupla presença do corpo: o corpo lá, na cena original dos eventos, e aqui, no momento da narrativa (OLIVEIRA, 2020, p. 82). 
O processo de subjugação dos fatos objetivos passíveis de comprovações àqueles que nos despertam sensações alinhadas às nossas visões de mundo caracteriza o fenômeno da pós-verdade (KEYES, 2018), ou seja, os sujeitos da contemporaneidade confiam naquilo que desejam ser a verdade a despeito dos fatos defendidas pelas instituições de poder do Estado moderno e dos veículos midiáticos confiáveis. Salgado (2018) sugere que a era da pós-verdade - e das políticas da pós-verdade - é produto das tecnologias midiáticas, do populismo e do relativismo da sociedade pós-moderna para o qual a verdade é sempre uma construção discursiva e depende do contexto no qual está inserida. O fenômeno não é exatamente uma novidade epistemológica, porém a intensidade com a qual as mídias digitais têm influenciado a fragmentação, individualização, flexibilização e relativização dos discursos é sem precedentes. Se a verdade desabar como um valor social, a continuidade das práticas sociais que ela sustenta pode estar gravemente comprometida.

Para refletirmos sobre a problemática da construção da verdade bolsonarista, partimos do pensamento foucaultiano ([1977-1978] 2008a; [1978-1979] 2008b) que sugere que para se ter um alcance político a análise tem de visar não a gênese das verdades ou a memória dos erros, mas a determinação do regime de verdade que foi instaurado num determinado momento para a legitimação da verdade como tal. Mostrar a falsidade dos enunciados pode ser uma estratégia política pouco efetiva, sendo necessário compreendermos o regime de produção de consensos - ou de dissensos - no qual os discursos são construídos para disputarmos valores neste terreno.

Em sua análise, o filósofo francês pensa o liberalismo clássico enquanto princípio e método da governamentalidade moderna, instaurando um regime de verdade que autolimita o poder do Estado e administra os problemas específicos da vida e da população a partir de princípios mercadológicos. Neste sentido, o liberalismo é pensado por Foucault ([1978-1979] 2008b) como princípio e método de racionalização das práticas de governo (governamentalidade) não mais pela "razão do Estado", mas pela regra interna da "economia máxima". 0 liberalismo rompe com a racionalização da prática governamental em nome da "razão de Estado" (existente desde o fim do século XVI e que implicava o fortalecimento e a maximização ótima da prática governamental, na medida em que a existência do Estado supõe imediatamente o exercício do governo).

Compreendendo o neoliberalismo como a forma que o liberalismo clássico se apresenta na contemporaneidade, Foucault observa que a generalização radical da racionalidade de mercado a áreas e atividades humanas não originalmente econômicas - natalidade, famí- 
lia, saúde, educação e sexualidade - funciona como o princípio de inteligibilidade que fundamenta as verdades e dá sentido às práticas sociais e às subjetividades. Além disso, o filósofo francês sugere que a biopolítica é a maneira pela qual se procurou, a partir do século XVIII, racionalizar os problemas postos às práticas governamentais dos fenômenos que emergiam nos grupos de viventes organizados em população: saúde, higiene, natalidade, educação, moradia, etc. (à luz das "leis naturais" do mercado). Fundamentalmente, o autor analisa o neoliberalismo como quadro geral da biopolítica, ou seja, esta forma de racionalização do mundo é uma das condições de inteligibilidade da biopolítica.

Para alcançar este pensamento, em seus estudos, Foucault ([1977-1978] 2008a.) investiga como pode ser regulado e medido o poder - e os regimes de verdade - em quem governa. Por muito tempo a ideia de regular, de medir e limitar o exercício do poder foi buscada numa sabedoria de quem governasse: "procurava-se governar pela verdade. Verdade do texto religioso, verdade da revelação, verdade da ordem do mundo, era isso que devia ser o princípio de regulamentação, de regulagem, melhor dizendo, do exercício do poder” (FOUCAULT, [1977-1978] 2008a., p. 422). A partir dos séculos XVI-XVII a regulagem do exercício passa a ser feita segundo o cálculo, isto é, cálculo das forças, cálculo das relações, cálculo das riquezas, cálculo dos fatores de poder. Não se procura mais regular o governo pela verdade, procura-se regulá-lo pela racionalidade. Regular o governo pela racionalidade é o que se poderia chamar de formas modernas de tecnologia governamental. É o que o pensador denomina de época da razão do Estado - racionalidade do Estado entendido como individualidade soberana; racionalidade liberal ou arte de governar pautada pelas decisões e atos dos agentes político-econômicos.

No entanto, a partir do final da década de 2010, este regime de verdade tem sido subjugado pela "conjectura da racionalidade liberal, poder masculino branco afrontado, nacionalismo e niilismo não declarado" (BROWN, 2018), legitimando energias afetivas que têm dado forma e conteúdo a formações e expressões políticas populistas e conservadoras em contextos econômicos marcadamente neoliberais. Neste sentido, a hipervalorização das experiências e crenças pessoais articulada por Oliveira (2000) e o relativismo pós-factual argumentado por Salgado (2018) estão diretamente relacionados a discursos emocionalmente inflamados e campanhas políticas articuladas por atores da extrema-direita por meio das redes sociais de Internet, assim como a campanha pelo Brexit, o posicionamento de Donald Trump sobre imigrantes e as narrativas bolsonaristas contra minorias identitárias.

No regime de historicidade contemporâneo, marcado pela aliança entre o neolibera- 
lismo e o neoconservadorismo, quais seriam as políticas, discursos, mecanismos e instâncias de poder capazes de distinguir o verdadeiro do falso? Considerando que a verdade situada em torno do real, da objetividade e da imparcialidade vem sendo continuadamente desconstruída pelos grupos da extrema-direita global, quais os métodos empregados pelo bolsonarismo para mobilizar a indignação antissistema e desestabilizar as instituições historicamente garantidoras da verdade, como a imprensa, a ciência e as instâncias independentes de poder do Estado moderno?

As questões levantadas neste artigo são extremamente complexas e não poderiam, de forma alguma, serem exaustivamente respondidas neste espaço. Entretanto, é nosso interesse articular a ascensão do que tem sido chamado de uma "nova direita global", de viés populista de direita e conservador, com a "crise da verdade" a partir de dois enfoques. Em um primeiro momento, propomos uma revisão teórica que toma o ressentimento e o ódio decorrentes do "poder masculino branco afrontado" como chaves de leitura para a compreensão do regime de verdade que tem sido instaurado pela aliança do neoliberalismo e do conservadorismo a partir, de pelo menos, o final da década de 2010. Em seguida, monitoramos a página oficial de Jair Bolsonaro no Facebook por 17 semanas - entre os dias 12 de março e 09 de julho de 2019 - para investigarmos empiricamente como o bolsonarismo mobiliza discursivamente o rancor daqueles que se sentem destituídos de um suposto direito nato de supremacia econômica política e cultural para a construção e comunicação de suas verdades.

\section{Metodologia}

Para analisarmos empiricamente como o bolsonarismo constrói e comunica os seus enunciados de verdade, monitoramos a sua página oficial no Facebook por 17 semanas (entre os dias 12 de março e 09 de julho de 2019), produzindo relatórios semanais dos conteúdos postados. 0 recorte temporal foi selecionado por abarcar quase quatro meses das atividades políticas desenvolvidas por Jair Bolsonaro nos primeiros meses do seu primeiro ano de mandato, por meio de conteúdos textuais comunicados quase que diariamente em sua página no Facebook.

Metodologicamente, investimos na Análise de Discurso Crítica (ADC) para estabelecermos alguns dos padrões de atuação de Bolsonaro, assim como os valores morais e posicionamentos ideológicos destacados nos enunciados postados pelo atual presidente brasileiro, uma vez que a análise de discurso tem como propósito o debate teórico e metodológico do 
discurso: a linguagem como prática social. ADC é caracterizada como uma abordagem metodológica que proporciona a interdependência entre interesses de pesquisa e compromissos políticos na análise de amplas unidades discursivas enquanto unidades básicas da comunicação, enfatizando a relação entre o que é comunicado e os processos sociais a essa comunicação. Considerando que "criticar é essencialmente tornar visível a interconectividade das coisas” (FAIRCLOUGH, 1985, p. 747), o método é capaz de trazer à luz as relações estruturais opacas e transparentes de dominação, controle, discriminação, poder e ideologia que se manifestaram a partir das narrativas com intenção de verdade que circularam no recorte temporal específico aqui investigado. Desta forma, descreveremos e analisaremos o discurso bolsonarista em um contexto sócio-histórico específico no Brasil contemporâneo.

Dialogando com autores como Fairclough, van Dijk, Fowler e Kress, Wodak (2001) enfatiza que o discurso em si é uma prática social usada em contextos específicos para a produção/manutenção do poder. A partir da perspectiva foucaultiana, a linguista austríaca observa que o discurso é também um meio para a representação das práticas sociais e uma forma de saber, assim como para os usos da linguagem como transformadora das representações do social. Partindo da compreensão dos discursos tanto como instrumentos de/do poder, da política e das transformações sociais da realidade para estabelecer um distanciamento epistemológico da postulação de simples relações deterministas entre o textual e o social, a ADC é uma método com interesse no texto e nas relações de poder e ideologia que a sua análise crítica pode revelar.

Para Wodak (2001, p. 11), o poder é exercido não apenas pelas formas gramaticais textuais, mas também pelos gêneros associados a determinadas ocasiões sociais. Refletindo a respeito dos gêneros das manifestações discursivas na criação ideológica e na vida, Bakhtin (1992) sugere que os diferentes campos da atividade humana são ligados ao uso da linguagem empregada na forma de enunciados articulados dialogicamente em diferentes textos. Apesar de cada enunciado particular ser individual, os diferentes campos de utilização da língua elaboram seus tipos relativamente estáveis de enunciados, denominados de gêneros do discurso. Deslocando a perspectiva bakhtiniana para a contemporaneidade de redes, analisaremos a "construção da verdade bolsonarista" por meio de discursos da comunicação digital resultantes das dinâmicas de poder e ideologia próprias que um ator político específico imprimiu a um conjunto de elementos caros à sociedade brasileira contemporânea em postagens feitas, quase que diariamente, no Facebook: ataques à imprensa, às instâncias independentes de poder e aos organismos de fomento à ciência, em oposição a um constante apelo ao nacionalismo, ao militarismo e à religiosidade 


\section{0 poder masculino branco afrontado e a construção de verdades individuais}

Embora ainda haja muita luta e resistência no caminho pela conquista da plena igualdade social, vivemos em uma era na qual o casamento entre pessoas do mesmo sexo é judicialmente reconhecido, permitindo que lésbicas e gays proclamem o seu amor e legalizem as suas relações; mulheres lideram governos nacionais e assumem posições de destaque em grandes corporações; minorias raciais e étnicas estão melhores integradas à vida cívica. Concretizado em mantras como o "Escola Sem Partido", "ideologia de gênero", "kit gay”, "maioria contra minorias", “defesa da família" e "Brasil acima de tudo, Deus acima de todos", autores como Kimmel (2013) e Brown (2018), postulam que o ódio de homens brancos, heterossexuais, cisgêneros, cristões e proprietários - uma metáfora que procura descrever os tradicionais chefes de família do modelo fordista de produção - tem sido atualizado no Brasil contemporâneo em reações violentas diante da emergência de novas gramáticas morais e mudanças culturais operadas pelas lutas dos movimentos LGBTQI+, feminista e negro. Em outras palavras, o ressentimento decorrente do poder masculino branco afrontado - que em uma perspectiva nietzschiana do termo condena moralmente o objeto responsável por sua humilhação - tem sido mobilizado e potencializado pelo bolsonarismo e outros governos populistas de direita através dos circuitos midiáticos, em especial as mídias sociais de Internet, estigmatizando e demonizando as minorias identitárias como culpados pelas suas mazelas.

Segundo Fassin (2019a), os líderes neoconservadores da direita global estrategicamente perceberam a potência política dos estereótipos de gênero e assimilaram que as questões sexuais não dizem respeito apenas a uma elite cultural, mas afetam a todas e todos, construindo verdades individuais sobre temas de interesse coletivo: sexualização infantil, pedofilia, ideologia de gênero, marxismo cultural, politicamente correto etc. A eficiência desses movimentos, portanto, é apostar na legitimidade e na manutenção das hierarquias de gênero e sexo para compor uma agenda sedutora para uma parte expressiva do eleitorado, jogando com os afetos na arena da intimidade para tornar a desigualdade desejável. Segundo o sociólogo francês, vivemos uma batalha tão política quanto emocional, na qual ressentimentos e temores estão levando ao poder homens e mulheres que reiteram em seus discursos de verdade (ultra)conservadores sobre a sexualidade humana: "É claro que a questão do gênero não esgota tudo o que está acontecendo, mas é um ângulo de entrada para entender muitas coisas" (FASSIN, 2019a, p. 4). 
Em quais contextos sociais a mobilização de sentimentos hostis às sexualidades tidas como perversas e degeneradas se dão para que a construção de múltiplas versões da verdade ocorra? Compreendo que a disseminação de discursos emocionalmente inflamados nas mídias digitais serve para reforçar crenças pessoais e coletivas, legitimando versões da verdade e energias afetivas que têm dado forma e conteúdo a redes de movimentos populistas neoconservadores em contextos econômicos marcadamente neoliberais. Neste cenário, os discursos com pretensão de verdade que a extrema-direita faz circular nos diversos espaços se apresenta como técnicas de governamentalidade neoliberal que, ao destituir um governo de esquerda e suas políticas inclusivas, privatiza a moralidade dos cidadãos de bem, enfraquece as forças periféricas, promove um golpe à democracia e, como já havia postulado Foucault nos anos 1970, estende a soberania da racionalidade de mercado a todas as áreas da existência humana para fortalecer ainda mais o capital financeiro.

O que ocorre, portanto, é que a política sexual e a política econômica andam, hoje em dia, de mãos dadas, articulando uma aliança antinatural entre os partidários do neoliberalismo e os defensores da tradição moral conservadora. Fassin (2019b), insiste que o Brasil de Bolsonaro não é uma exceção no cenário mundial, mas "o laboratório interseccional do neoliberalismo" (FASSIN, 2019b), ou seja, um exemplo político-cultural a ser seguido globalmente, servindo para ilustrar uma deriva populista de direita que afeta outros países em outras partes do mundo, assim como os Estados Unidos de Donald Trump, a Turquia de Erdoğan, a Hungria de Orban ou as Filipinas de Duterte. Conforme Fassin (2019b) insiste, podemos fazer, então, um paralelo com o Chile de Pinochet que, após o golpe de Estado de 1973, serviu de laboratório para o neoliberalismo - tanto no Chile do passado quanto no Brasil recente, tratou-se também de se dar lugar aos “Chicago Boys”. Estrategicamente, no caso brasileiro, a virada neoliberal tardia de Jair Bolsonaro durante a campanha para a eleição presidencial de 2018, pode ser resumida na escolha de Paulo Guedes para gerir a pasta da Economia, acalmando, assim, as ansiedades das elites financeiras. Conforme o intelectual francês sintetiza, o neoliberalismo é hoje antiliberal, ou seja, o sistema ideológico do capitalismo se mostrar moral e sexista:

Por que o gênero? Porque precisamente, o que aconteceu nos últimos anos é que a ordem sexual mudou visivelmente (...). Por que Trump quer afirmar seu sexismo? Por que Bolsonaro quer acrescentar de alguma forma nessa encenação de uma masculinidade heterossexual triunfante? Por quê? Porque precisamente a ordem sexual é importante. É assim que se ganharam eleições. Essa não é uma questão periférica, não um problema para as minorias, 
as questões das minorias afetam a ordem social. Nós já sabíamos, mas agora está claro que eles estão em jogo na democracia" (FASSIN, 2019b, p 6-9).

Alguns anos antes Kimmel (2013) já havia alertado que a era dos direitos masculinos inquestionáveis e incontestados havia acabado, deixando os homens brancos heterossexuais com ódio e um desejo nostálgico aos velhos tempos, quando eram os únicos que se beneficiavam da dramática desigualdade social historicamente dominante. Portanto, machos ressentidos e rancorosos procuram diferentes meios de "restaurar, restabelecer, reivindicar algo que é percebido como perdido" e "acreditam que o sistema está contra eles” (KIMMEL, 2013, p. 21). Na mesma linha de raciocínio, Brown (2018, p. 60) sugere que políticos - nos moldes de Donald Trump, Marine Le Pen, Viktor Orbán e Jair Messias Bolsonaro - mobilizam não apenas o ressentimento de classe, mas "especialmente o rancor masculino branco, sobre o orgulho perdido (social, econômico, cultural e político) no contexto de quatro décadas de neoliberalismo e globalização".

Com a implementação do neoliberalismo como racionalidade da arte de governar contemporânea, homens brancos, heterossexuais, cisgêneros, cristões e proprietários sentem terem perdido a sua dignidade com o desmantelamento dos sindicatos, a flexibilização das leis trabalhistas e dos salários, o fechamento dos portões das fábricas e alterações nas políticas de Bem-Estar Social. Homens historicamente privilegiados e unidos pela crença em um ideal de masculinidade percebem que o neoliberalismo traz perdas ao seu direito nato à supremacia política, social e econômica, porém deslocam a culpa das derrotas impostas por instituições governamentais e financeiras para sujeitos menos poderosos, sejam eles imigrantes, negros, mulheres, feministas, homossexuais ou pessoas trans.

Para o pensamento neoliberal, a sociedade constitui o alvo de algum tipo de intervenção governamental, porém não para restringir de forma autoritária as liberdades individuais formalmente concedidas e sim para produzir, multiplicar e garantir o valor, o posicionamento competitivo e a participação de mercado de pessoas ou empresas. No entanto, segundo Brown (2018), novas iterações e expressões de liberdade foram elaboradas a partir da conjectura da racionalidade neoliberal, poder masculino branco afrontado, nacionalismo e niilismo não declarado. Para a intelectual estadunidense, os efeitos da racionalidade neoliberal em contextos histórico-sociais que privilegiavam a soberania do homem branco heterossexual e cristão, o deslocamento das forças sociais, ataques ao político e o amplo descrédito das normas democráticas têm alimentado e legitimado energias afetivas que dão 
forma e conteúdo a formações e expressões políticas neoconservadoras de direita na contemporaneidade, assim como àquelas que auxiliaram Bolsonaro a se eleger presidente da República no Brasil em 2018.

Ao analisar o processo de construção histórica do atual regime do self, Rose (1998) enfatiza que a liberdade, escolha e responsabilidade pessoal são obrigações éticas do ethos constitutivo do humano contemporâneo, sendo instrumentalizadas por meio das ciências psi como tecnologias da autonomia em processos de universalização do sujeito neoliberal e conhecimento de sua subjetividade como forma de controle governamental. Em um contexto no qual a fusão da liberdade defendida pela racionalidade neoliberal com o neoconservadorismo, autoritarismo, exclusão social legitimada e diversas formas de violência contra as subjetividades dissidentes possui um grande apelo entre grupos populacionais, Brown (2018) problematiza o conceito de liberdade enquanto força política que age sobre a vida e os corpos, definindo-a como uma "liberdade autoritária" que estabelece os limites da normatividade de acordo com os valores familiares e particulares, além da rejeição do político e do social em nome das leis supostamente espontâneas mercado. Para Brown (2018, p. 67), quando a esfera das verdades e crenças pessoais é estendida ao particular, quando a oposição à regulação se torna um princípio fundamental, quando o social é rebaixado e o político é demonizado, o animus individual e os poderes históricos do domínio do homem branco são desencadeados e legitimados.

\section{A construção discursiva da verdade bolsonarista}

Nomeado pela revista Times como "o cérebro de Trump", Steve Bannon seria o responsável pela criação do aspecto ideológico que tem guiado a direita alternativa (alt-right) norte-americana e os movimentos populistas conservadores globais, desenvolvendo infraestruturas, linguagens e ferramentas das mídias sociais para o fortalecimento de veículos midiáticos de caráter sensacionalistas e vorazes. Para Alexander (2018), Trump, enquanto personagem performático instruído e projetado por Bannon, engaja o ressentimento daqueles que se veem como outsiders e excluídos pelo establishment em uma luta contra as ideias e o espírito da democracia a partir de categorias binárias simplificadoras e narrativas temporais excludentes: o discurso universalista é antiquado, as instituições independentes são disfuncionais, o jornalismo é falso, as pesquisas de opinião pública são fraudulentas, a justiça é tendenciosa, o voto não é conclusivo e o cargo não é vinculativo. 
O modus operandi de Jair Bolsonaro - importado pelo "guru" da extrema-direita brasileira, Olavo de Carvalho - se insere neste movimento da ascensão da extrema-direita e da indignação antissistema em escala mundial. A indiferença em relação à veracidade constitutiva dos valores modernistas é instrumentalizada por táticas de guerras culturais (HUNTER, 1991) aos valores democráticos e ao humanismo emancipatório, ou seja, às ideias, instituições e formas de existência que idealizam direitos universais e proclamam a favor da diversidade humana. Temas há pouco restritos a teorias da conspiração - nova ordem mundial, globalismo, negacionismo científico, terraplanismo e marxismo cultural - se tornaram presentes em polêmicas articuladas pelo presidente brasileiro através das suas redes digitais. Neste contexto, a sua página oficial no Facebook merece destaque na mobilização da hostilidade popular aos discursos dominantes na mídia, universidades, ciências, Congresso e STF, enfim, a qualquer obstáculo que se imponha contra o bolsonarismo e à construção de sua verdade.

Para Olavo de Carvalho $(2016)^{4}$, os cientistas, historiadores e intelectuais "alegam trabalhar com evidências, mas e se as evidências já estão influenciadas pelo marxismo cultural como pode o método operado ser verdadeiro?”. Em outras palavras, para o pensamento que serve de base para a ala radical do neoconservadorismo brasileiro a produção científica ocidental está condicionada por uma estrutura dada a priori que subverte os valores essenciais da civilização judaico-cristã. Como sugere oliveira (2018, p. 84), a emancipação a essa conspiração internacional marxista se daria, portanto, pela ação voluntariosa de pensadores livres capazes de construir saberes pautados na observação direta e independente da realidade para a construção das suas próprias versões da verdade.

Entretanto, a questão não é tão simples quanto proposta pelo olavismo. Os enunciados de saber-poder construídos a partir das observações diretas de homens livres e emancipados não são resultantes tão somente das suas ações voluntariosas, mas experiências condicionadas pela visão de mundo que governa estes corpos em um contexto histórico bastante específico. O negacionismo, o anticientificismo e a subversão das instituições de poder do Estado moderno em defesa das verdades e dos valores morais conservadores propostos por Olavo de Carvalho - e amplamente defendidos pelo presidente Jair Bolsonaro - estão subjetivamente vinculados a um regime de verdade neoliberal-neoconservador que, ao mobilizar

\footnotetext{
${ }^{4}$ Cf.: Marxismo cultural no Brasil. In: YouTube, 16 de março de 2016. Disponível em: https: //www.youtube.com/ watch?v=30ftHc9iF6Y. Acesso em: 09 de maio de 2020.
} 
discursivamente o ressentimento do homem branco, heterossexual, cisgênero, cristão e proprietário pelas redes sociais de Internet, o legitima como princípio de inteligibilidade da sua verdade.

\subsection{Ataques às instituições de poder do Estado moderno}

"Respeitamos a todas as instituições, mas é ao povo a quem devemos lealdade" (BOLSONARO, 05 de julho de 2019). Em nome de um populismo de direita reacionário, o bolsonarismo promove ataques sistemáticos, produzindo um curto-circuito nos arranjos político-institucionais do país para a construção de suas verdades. Durante as 17 semanas que o perfil do presidente foi monitorado pela pesquisa, observamos que, em momentos críticos do seu governo, Bolsonaro constrói narrativas a seu favor denunciando as críticas recebidas como fake news e apontando os veículos midiáticos que as publicam como defensores dos interesses da uma suposta esquerda socialista. No meu entender, essa estratégia comunicacional procura construir múltiplas versões da verdade, alimentando dúvidas nos cidadãos comuns desiludidos com o sistema para que os mesmos se informam por canais midiáticos não-tradicionais sobre os fatos e os eventos reais. Desta forma, em 07 de abril de 2019, acusa a mídia nacional de ser suja e explorar, de forma negativa e sorrateira, suas colocações para expor, 24 horas por dia, um presidente que não lhes dá o que querem. 0 que observamos é a tentativa de comunicar - via Facebook - uma estratégia de "restauração nacional da desgraça deixada pelo PT", relegando as muitas críticas midiatizadas contra o seu governo como desinformação em defesa de interesses de grupos ideologicamente ligados à esquerda.

Após sucessivos desgastes no ministério da Educação, como a publicação de um edital que alterava as regras para compras de livros didáticos e o envio de cartas a diretores de escolas pedindo que eles filmassem alunos cantando o Hino Nacional, Bolsonaro confessou sofrer “bombardeios diários de fake news como esse caso da 'demissão' do Ministro Velez. Com mentiras a mídia cria narrativas de que NÃO GOVERNO, SOU ATRAPALHADO, etc.". Contrariando esta postagem, no dia 8 de abril de 2019, via Twitter, o presidente agradece os serviços prestados pelo Prof. Velez e comunica a indicação de Weintraub para a pasta da Educação.

Em outro momento, quando seu filho Carlos publicou em uma rede social mensagens com críticas ao vice-presidente e aos militares, Bolsonaro postou jamais ter visto "uma perseguição tão infantil e sem sentido por parte de certos 'veículos de informação' a uma pessoa, constantemente mostrando este e outros exemplos banais". Para defender as reformas 
propostas pelo seu governo - dentre elas, a previdência, a tributária e a trabalhista - convoca a população a não se deixar manipular por desinformações e interesses de terceiros, alertando que "quando não há problemas no governo, a maior parte da mídia inventa alguma para ter o que falar e manipular. Informe-se sempre buscando uma mídia alternativa, pois infelizmente muitas dos habituais não querem o melhor para o Brasil, somente para si mesmas!”.

Argumentamos que, para projetar alguma forma de estabilidade no setor educacional, dentre outras ações e programas promovidos, em 26 de novembro de 2020, o governo Bolsonaro publicou um decreto que almeja instituir a estratégia federal de desenvolvimento para o Brasil no período de 2020 a 2031. O decreto aposta em melhorias de índices educacionais tais como Índice de Desenvolvimento da Educação Básica (Ideb), Programa Internacional de Avaliação de Alunos (Pisa), e aumento da porcentagem de estudantes que concluem o Ensino Fundamental. Este, talvez, seja um caminho para que os ressentidos "cidadãos de bem" retomem a confiança no falido sistema educacional brasileiro. Porém, para o professor José Marcelino de Rezende Pinto, da USP, pesquisador em financiamento da educação, as projeções são irreais em um contexto de falta de mais recursos na educação ${ }^{5}$.

Paradoxalmente, acionando a estratégia discursiva de terceirização da responsabilidade, durante o \#15M - o dia em que estudantes, educadores(as), pais, sindicatos e movimentos diversos, em nome da educação, pararam o Brasil e atos tomaram as ruas para marcar a Greve Nacional da Educação, em 15 de maio de 2019 -, classificou os manifestantes de "idiotas úteis", acusando o socialismo de gerar o mal generalizado. Alimentando as narrativas que publicizam as políticas antipetistas por justiça social que a "masculinidade branca" culpabiliza pela perda de seus privilégios históricos, o presidente da República endossa o discurso neoconservador-neoliberal de que o país é "ingovernável" sem os "conchavos" que o bolsonarismo se recusa a fazer, acusa Dilma de ter cortado $\mathrm{R} \$ 10$ bilhões da Educação e ter doado $\mathrm{R} \$ 50$ bilhões para países amigos (ditaduras comunistas): “Quem participou dessa última manifestação e não tinha conhecimento disso, eu lamento, mas foram usados como massa de manobra pelo bando do 'Lula livre'”. Mais adiante - para se mostrar um governante forte - apela com imagens da visita de alunos no Alvorada: "É pelo futuro dessas crianças o nosso maior empenho. Agradeço a Deus pela minha vida e pela MISSÃO de conduzir os destinos do Brasil”. Desta forma, Bolsonaro aposta na retórica de verdade que associa a sua imagem à representação simbólica da infância, compartilhando vídeos nos quais recebe visitas de alunos de diferentes escolas.

\footnotetext{
5 Fonte consultada: https: / /bit.ly/3sAlbe1. Acesso em: 30 de março de 2021
} 
Apesar de repetidamente defender a liberdade de imprensa como um dos pilares fundamentais para a democracia, Bolsonaro privilegia canais de mídia específicos, deslocando o fenômeno das "bolhas digitais" para os meios de comunicação tradicionais. Neste sentido, concede entrevistas e faz aparições exclusivas nos veículos midiáticos que o apoiam. Por exemplo, em 05 de maio, participou do Programa Silvio Santos, no SBT, em entrevista sobre a "Nova Previdência"; no dia 07 de maio foi ao ar entrevista com Luciana Gimenez na RedeTv!; em 12 de maio, Milton Neves entrevistou o presidente ao vivo na Rádio Bandeirantes. Durante os protestos contra e a favor dos cortes na educação concedeu entrevista exclusiva ao Domingo Espetacular, na Record; recebeu visita de Carlos Alberto de Nóbrega (apresentador da Praça é Nossa no SBT); participou do programa The Noite com Danilo Gentili, no SBT; apareceu no Programa do Ratinho, também no SBT; compartilhou diversos áudios de Alexandre Garcia, parabenizando o jornalista pela "sua imparcialidade de sempre [que] orgulha o bom jornalismo". O que observamos no discurso bolsonarista é uma tentativa de comunicar os inúmeros fracassos de seu governo como desinformação e estimular os seus seguidores, muitos deles ressentidos com o sistema político-midiático vigente, a procurarem fontes de mídia alternativas para se informar de forma confiável, ou seja, consultarem meios de comunicação alinhados ideologicamente às suas posições e que defendam os seus ideais neoconservadores-neoliberais.

Paradoxalmente ao que tem sido publicado nos principais jornais do país e do mundo, Bolsonaro posta eventos e ações de seu governo que veiculam uma fictícia sintonia e eficiência entre os diversos ministérios e esferas governamentais. Em 09 de abril, compartilhou um vídeo no qual sintetiza os investimentos que o seu governo fez, em pouco menos de 100 dias no poder, e o retorno que a população tem recebido (o vídeo tem 2 horas e 07 minutos e teve 107.161 visualizações, até o dia 08 de maio de 2019). Desta forma, constrói a sua versão discursiva de episódios polêmicos, publicando ações do ministro do Meio Ambiente, Ricardo Salles, em benefício do meio ambiente; a inserção social indígena em uma iniciativa da Embrapa e da Funai: "Chega de tratar nossos irmãos como animais de zoológico ou como massa de manobra política"; um levantamento baseado em dados oficiais dos estados que aponta queda de 25\% dos assassinatos no Brasil no primeiro trimestre de 2019 em relação ao ano passado; um estudo que evidencia que a Nova Previdência gerará economia de 1 trilhão de reais ao país: "Teremos condições de potencializar nossos investimentos como nunca, sendo preciso consciência e patriotismo para entender que o que está em jogo é a construção de um futuro próspero para todos". 
Paradoxalmente, em outros momentos, a desarticulação com o Legislativo e o Judiciário serve estrategicamente para a terceirização de problemas e da responsabilidade de governar. Por exemplo, em 13 de maio, declara que o trabalho conjunto dos ministérios do governo Bolsonaro, pincipalmente com o Ministério da Justiça e Segurança Pública, vem rendendo excelentes expectativas (mesmo que o Congresso Nacional ainda não tenha analisado projetos de apelo sociais vitais para o combate à insegurança pública, como o pacote anticrimes e tantos projetos de interesse social) e, em 07 de junho, apela à responsabilidade e patriotismo dos deputados e senadores pela aprovação do PLN 4 (da qual dependeria o pagamento de benefícios a idosos, pessoas com deficiências e aposentados). E, seguida, no dia 15 de junho, anuncia que a Comissão de Justiça do Senado decidiu revogar os decretos sobre os CACs (caçadores, atiradores e colecionadores) e posse de armas de fogo, convocando os “cidadãos de bem" a ligarem para os senadores de seus estados e pressionarem contra o Projeto de Lei a ser votado, que sustaria o Decreto 9785/2019. Finalmente, em 18 de junho, lamenta a derrota no Senado, por 47 votos a 28, e pressiona por apoio da Câmara ao Decreto sobre CACs e Posse de Armas de Fogo.

Ao ser publicamente acusado de incitar a população contra o Legislativo e o Judiciário, o presidente ataca o jornalista da Folha de São Paulo, Celso Rocha de Barro, que "diz que quero fechar o Congresso e o STF, censurar a imprensa e perseguir a esquerda". Construindo e comunicando a sua versão da verdade a partir das suas experiências e do ataque ao inimigo, lembra "ao jornal que não fui eu que anulei o legislativo comprando votos, não fui eu que tive em meu plano de governo o controle da mídia e da internet e FUI EU QUEM LEVOU UMA FACADA de um militante de esquerda. Mais uma vez, 100\% Fake News!”. Quando os atos de 26 de maio em seu favor foram acusados de antidemocráticos, Bolsonaro procurou se desassociar dos discursos que pediam o fechamento do Congresso Nacional e do STF: "Acredito na harmonia, na sensibilidade e no patriotismo dos integrantes dos três Poderes da República para o momento que atravessa nossa Nação".

Desta forma, o atual presidente tenta articular discursivamente e gestualmente que Executivo, Legislativo e Judiciário são as três instâncias governamentais que, em seu governo, trabalham harmoniosamente para resolver as mazelas deixadas pelos governos petistas (2003-2016). Somente a título de curiosidade, para entendermos alguns indicadores sobre a relação entre o governo Bolsonaro, o Congresso e o Judiciário, somente em 2019, seu primeiro ano de mandato, o governo Bolsonaro foi alvo de 58 Ações Diretas de Inconstitucionalidade pelo STF. Nesta mesma direção, 48 medidas provisórias foram editadas pelo presidente, 
mas não foram aprovadas pela Câmara e pelo Senado no período requerido de até 120 dias, fazendo que tais MPs caducassem e perdessem a validade, assim como $29 \%$ das leis aprovadas pelo Congresso foram vetadas pelo presidente - certas partes ou mesmo todo o seu conteúdo. Porém, o Congresso tem o poder de derrubar esses vetos e fazer com que os dispositivos vetados passem a valer novamente ${ }^{6}$.

Em direção oposta ao que Bolsonaro tenta projetar publicamente, em reportagem publicada em 22 de junho de $2020^{7}$, foi anunciado que militares montam operação de guerra para 'salvar' governo Bolsonaro que teria começado a ser executada há pelo menos um mês (maio de 2020), mas teria ganhado força depois da prisão de Fabrício Queiroz - responsável pelo esquema das "rachadinhas" no gabinete do então deputado federal e filho do presidente, Flávio Bolsonaro, na Assembleia Legislativa no Rio de Janeiro. A matéria sugere que os militares vêm tentando pavimentar uma ponte para melhorar as relações de Bolsonaro com o Judiciário, sobretudo com os ministros do Supremo Tribunal Federal (STF). A mais alta corte do país conduz dois inquéritos que podem resultar em estragos monumentais ao governo. Um se refere à disseminação de fake news; outro, ao financiamento de manifestações antidemocráticas. Esses inquéritos do STF vão se cruzar, em algum momento, com os processos que tramitam no Tribunal Superior Eleitoral (TSE) que pedem a cassação da chapa Bolsonaro-Mourão. A operação de guerra conseguiu, pelo menos por hora, segurar todos os processos de impeachment de Bolsonaro que deram entrada na Câmara dos Deputados.

Neste contexto beligerante de disputas por poder e verdade, no qual o sistema de freios e contrapesos é posto em xeque, manifestantes bolsonaristas ressentidos com o Legislativo e o Judiciário foram às ruas clamar pelo fechamento do Congresso e do STF. O próprio presidente da República compareceu a alguns desses atos em Brasília, o que, na visão de integrantes do STF e da sociedade civil organizada, é um sinal perigoso para a democracia brasileira, já que publicamente ocorre o reforço do pedido de intervenção militar no país para conter, especialmente, o Judiciário. Finalmente, em 12 de junho de 2020, o ministro do STF, Luiz Fux, concedeu uma liminar delimitando a interpretação da Constituição e da lei que disciplina as Forças Armadas. Na decisão judicial, ele esclareceu que ela não permite a intervenção do Exército sobre o Legislativo, o Judiciário ou o Executivo. Não é um poder moderador, afirmou na decisão.

\footnotetext{
6 Fonte consultada: https: / / bit.ly/2QPM6Vo. Acesso em: 30 de março de 2021.

7 Disponível em: https://bit.ly/3weP1Y2. Acesso em: 30 de março de 2021.
} 
No que tange às instituições de fomento à produção científica, Bolsonaro estabelece uma complexa relação. Por um lado, promove conquistas que claramente dependem de pesquisa e desenvolvimento científico, como aquelas relacionadas aos ministérios da Ciência, Tecnologia, Inovações e Comunicação, do Meio Ambiente, da Agricultura, Pecuária e Abastecimento, do Desenvolvimento Regional e outras áreas técnicas do seu governo. Por outro, ataca instituições e setores da educação que ainda estariam sob a influência dogmática dos 13 anos de governo petista - revelando um alinhamento ideológico ao negacionismo científico propagado por Olavo de Carvalho. No mesmo dia em que declara que São Paulo terá o maior Colégio Militar do Brasil, anuncia que o ministro da Educação, Abraham Weintraub, estuda descentralizar investimento em faculdades de filosofia e sociologia (humanas): “ 0 objetivo é focar em áreas que gerem retorno imediato ao contribuinte, como: veterinária, engenharia e medicina". Posteriormente, denuncia "a mentira do corte de 30\% nas Universidades", compartilhando vídeo no qual Weintraub explica a diferença entre "corte" e “contingenciamento".

Compreendemos que por meio do poder que o cargo de chefe do Executivo lhe concede, Bolsonaro já negou a ciência em diversas oportunidades desde que ascendeu ao poder em um diálogo direto com os seus apoiadores que desconfiam do cientificismo. Primeiramente, em janeiro de 2020, o presidente Jair Bolsonaro criticou a decisão do STF de proibir a chamada "pílula do câncer" - a decisão da Corte em barrar o medicamento baseou-se na falta de comprovação de científica após a realização de testes. Logo em seguida, em julho de 2020, o governo exonerou a coordenadora-geral de Observação da Terra do Instituto Nacional de Pesquisas Espaciais (Inpe), dias depois de o Inpe divulgar que a Amazônia teve o maior número de alertas de desmatamento desde 2015. Durante o início da pandemia de Sars-CoV-2 no Brasil, com o primeiro caso oficializado em 26 de fevereiro de 2020 , o presidente se colocou contra o isolamento social e o fechamento do comércio, advogando pelo isolamento vertical, assim como fez inúmeras aparições públicas sem máscara e vetou a obrigatoriedade do uso do equipamento de proteção no comércio, em escolas e em igrejas. Finalmente, mesmo sem qualquer tipo de comprovação científica de que a (hidroxi)cloroquina fosse eficiente no tratamento contra a Covid-19, o governo do Brasil comprou milhares de doses do medicamento. 0 medicamento foi pivô da saída de dois ministros da Saúde: Luiz Henrique Mandetta e Nelson Teich que discordaram das ações e posições do presidente à época8 ${ }^{8}$.

\footnotetext{
${ }^{8}$ Fonte consultada: https://bit.ly/3ddwMcE. Acesso em: 30 de março de 2021.
} 


\subsection{Apelo aos valores morais conservadores}

Paralelamente aos ataques promovidos, Bolsonaro exalta o nacionalismo, empreendendo uma verdadeira cruzada internacional para "limpar a imagem do Brasil no exterior" e reconquistar a confiança para o fomento de investimentos e acordos em áreas como comércio, ciência, tecnologia, defesa e segurança, principalmente com os Estados Unidos de Donald Trump. Em 17 de março, "Pela primeira vez em muito tempo, um Presidente brasileiro que não é anti-americano chega a Washington", assustando os defensores do atraso e da tirania ao redor do mundo ao iniciar uma parceria pela liberdade e prosperidade. Desta forma, o bolsonarismo articula o processo de construção das identidades individuais e coletivas do povo brasileiro (CASTELLS, 2010) aos valores, estilos de vida, crenças e comunidades organizadas a partir dos ideais neoconservadores-neoliberais norte-americanos. Outras viagens e acordos de "comércio sem ideologia" foram oficialmente estabelecidos, assim como em Israel, Buenos Aires, Alemanha, os países islâmicos, União Europeia e o G-20. Paradoxalmente, formalizou a decisão do Brasil de deixar a União das Nações Sul-Americanas (Unasul), enfatizando que a instituição "nasceu em 2008 como um projeto do então presidente da Venezuela, Hugo Chávez, sendo apoiado por Lula”.

Observamos, no discurso bolsonarista, o nacionalismo e o patriotismo serem acionados como motes de salvação aos anos de corrupção ideológica e moral aos quais o país foi acometido pelos governos esquerdistas. 0 apelo à retórica nacionalista não é nenhuma novidade histórica, mas ela, geralmente, vem acompanhada de argumentos anticolonialistas. As narrativas bolsonaristas vêm acompanhadas de um discurso entreguista e subserviente aos Estados Unidos no plano da política externa, especialmente às políticas lideradas por Donald Trump - que esteve no poder até 20 de janeiro de 2021. Na construção da sua verdade, Bolsonaro ignora que, em nome do nacionalismo, durante a ditadura militar, houve torturas, exílios, assassinatos e desparecimentos de corpos de adversários políticos, preferindo denominar este período da recente história brasileira de "revolução democrática".

Compreendemos, portanto, o discurso nacionalista proferido por Bolsonaro como uma arma política por meio da qual o retrocesso e a barbárie são justificados. "Brasil, ame-o ou deixe-o" foi o slogan do período da ditadura militar brasileira regatado por uma série de vinhetas exibidas pelo SBT, em 06 de fevereiro de 2018. Embora não diretamente associado à construção discursiva da verdade bolsonarista, o slogan expressa a construção dos cidadãos de esquerda como inimigos da pátria antes da votação do segundo turno quando, por trans- 
missão das imagens de um telefone celular para um telão na Avenida Paulista, Bolsonaro falou durante um ato organizado pelo PSL em São Paulo: “Nós somos a maioria. Nós somos o Brasil de verdade. [...] Essa turma, se quiser ficar aqui, vai ter que se colocar sob a lei de todos nós. Ou vão para fora ou vão para a cadeia. Esses marginais vermelhos serão banidos de nossa pátria"?.

A tentativa de vinculação nacional por meio do seu populismo, que tem quantitativamente dependendo das suas ações e reações públicas, também é alimentada a partir do futebol, considerado uma das mais importantes fontes de significado e experiência do povo brasileiro (CASTELLS, 2010). O presidente se associa a jogadores, como Neymar e Ronaldinho Gaúcho, faz aparições em jogos da seleção brasileira na Copa América e agradece às meninas do futebol "por bem representar o Brasil no Mundial Feminino na França”. O simbolismo do futebol serviu para comunicar o seu apoio ao ministro Sérgio Moro durante o escândalo da Vaza Jato, postando vídeo no qual ele vai ao Estádio Mané Garrincha assistir Flamengo x CSA acompanhado de Moro após ter evitado comentar sobre o caso, inclusive abandonando entrevistas coletivas.

“O Brasil tem seus heróis de ontem, de hoje, de sempre... Como Chefe do Supremo das Forças Armadas minha continência e meu muito obrigado ao eterno Comandante, general Villas Bôas" (BOLSONARO, 05 de julho de 2019). A defesa do militarismo é outro sentido discursivo predominante na construção da verdade bolsonarista. 0 presidente declara ter chegado "na Câmara em 1991 e encontrei-a tomada pela esquerda num clima hostil às Forças Armadas e contrário às nossas tradições judaico-cristã. Aos poucos outros nomes foram se somando na causa que defendia, entre eles Olavo de Carvalho". O presidente se empenha em restituir a ordem participando de atividades militares, como a Cerimônia Comemorativa do Dia do Exército, acionando um canhão militar na $9^{\text {a }}$ GAC de Nioaque (MS) em comemoração ao Dia da Artilharia, comemorando o aniversário do Batalhão da Guarda Presidencial e celebrando os 20 anos do Ministério da Defesa que teria surgido em 1999 não por necessidade militar, mas por uma imposição política: “A verdade acima de tudo!”.

Em 27 de março, o presidente compartilha um texto comemorativo no qual afirma que nós brasileiros participamos da "Revolução de 1964, identificados com os anseios nacionais de preservação das instituições democráticas, ameaçadas pela radicalização ideológica, greves, desordem social e corrupção generalizada". No entanto, 02 dias depois, a Juíza Ivani

\footnotetext{
${ }^{9}$ Disponível em: https://bit.ly/2FsBXIw.Acesso em: 14 de agosto de 2020.
} 
da Luz, da $6^{\text {a }}$ Vara da Justiça Federal em Brasília, proibiu o governo de comemorar o aniversário de 55 anos do golpe de 1964 com cerimônia solene que seria realizada no domingo, dia 31 de março. Ao promover a preservação da memória e da cultura militar, o discurso bolsonarista nega o golpe de 1964 e a ditadura militar brasileira (1964-1985), construindo e comunicando versões conservadoras da história nacional que representam os anos de chumbo do nosso passado recente como uma alegada "revolução democrática" contra a ameaça comunista pretensamente em curso.

Entendemos que os discursos revisionistas e negacionistas ao golpe de 1964 e à ditadura militar brasileira (1964-1985) têm sido estrategicamente acionados pelo bolsonarismo para a construção e a comunicação de sua verdade. Este fenômeno tem sido alimentado pela emergência dos fenômenos do revisionismo e do negacionismo histórico potencializados no contexto contemporâneo marcado pelas redes sociais digitais, pela formação das verdades e crenças pessoais em oposição ao processo historiográfico científico e pela ascensão ao poder da extrema-direita que tem deslocado o sentido nas palavras comunista, comunismo e esquerda. Neste sentido, a defesa da militarização do seu governo, para além de desviar as Forças Armadas de seu papel constitucional, satisfaz os bolsonaristas antissistema e nostálgicos pela ordem e segurança que os anos da ditadura representam em suas memórias. Em seu governo, Bolsonaro tem dado à militarização um espaço inédito pós-redemocratização, colocando generais em postos-chave para a gestão nacional. Acreditamos que esse apoio ao militarismo continuará no pleito de 2022 como uma estratégia discursiva para comunicar midiaticamente a exaltação dos feitos da ditadura militar e a possibilidade do resgate da lei e da ordem nacionais àquelas e àquelas ressentidos com as mudanças que a Constituição Federal de 1988 trouxe para a realidade brasileira.

Para além do nacionalismo e do militarismo, a religiosidade, mais especificamente o cristianismo, é o terceiro pilar discursivo na construção da verdade bolsonarista. Segundo Bolsonaro, "E conhecereis a verdade, e a verdade vos libertará" (JOÃO, 8:32) é a mensagem bíblica que tem estado sempre à frente da sua missão presidencial. Apesar do princípio da laicidade, exposto no texto da Constituição Federal de 1988, pregar a desagregação da religião e seus valores sobre os atos governamentais, o presidente segue afirmando em palavras e ações o slogan de campanha e de governo "Brasil acima de tudo, Deus acima de todos”, além de repetidamente compartilhar passagens bíblicas em sua página oficial do Facebook. Bolsonaro chegou a questionar a necessidade de se ter um ministro evangélico no STF: “O Estado é laico, mas eu sou cristão. Não está na hora de o Supremo ter um ministro evan- 
gélico?". Ao suplicar a proteção divina e projetar o seu slogan de campanha "Brasil acima de tudo, Deus acima de todos", sintetizando o "Brasil de um só povo" que não foi corrompido pelas mudanças morais que o mundo vem sofrendo contemporaneamente, o bolsonarismo associa as suas políticas neoliberais-neoconservadoras à proteção e o resgate dos valores da família tradicional e dos "cidadãos de bem”. Paradoxalmente, conforme noticiado pelo site do Congresso em foco, durante as eleições presidenciais de 2018, das 123 fake news encontradas por agências de checagem, 104 beneficiaram Bolsonaro diretamente ${ }^{10}$.

A promoção discursiva da religiosidade na construção da verdade bolsonarista serve para reiterar o compromisso estabelecido com seus apoiadores de colocar em prática o projeto de Brasil que fez ecoar nos circuitos midiáticos amplificados durante a campanha eleitoral e durante os sete termos que atuou como deputado federal (1991-2018). Portanto, em grande parte de suas postagens, comunica que "Peço ao bom Deus que nos dê sabedoria para conduzir a nação" e "Que Deus abençoe esta grande nação". Ao ser empossado como $38^{\circ}$ presidente da República Federativa do Brasil, em 01 de janeiro de 2019, o novo chefe do Executivo reafirmou no primeiro pronunciamento à nação o seu ideal de país conduzido por um "Deus acima de todos" contra a "desconstrução da família” e a "ideologização de nossas crianças". Neste discurso inaugural, ao convocar a união do "poder masculino branco afrontado" contra um inimigo que supostamente ameaçava "dividir os brasileiros", Bolsonaro reafirmou os componentes hierárquicos implícitos em sua promessa de um "Brasil acima de tudo": a inversão de valores religiosos e morais, o politicamente correto, ideologias nefastas que que destroem nossos valores, tradições e famílias, assim como padrões éticos e morais que dividem o país entre "bons" e "maus" brasileiros - sendo os "cidadãos de bem" compreendidos em sua narrativa como os seguidores das tradições judaico-cristãos.

\section{Considerações finais}

Por meio do monitoramento e da análise das postagens de Jair Bolsonaro em sua página oficial no Facebook por 17 semanas, procuramos suspender julgamentos imediatos - que colocam as falas do presidente brasileiro na pecha da insanidade, loucura e ignorância, focando metodologicamente na Análise de Discurso Crítica - apoiados pelos aportes e diretrizes teóricas postulados por Fairclough (1989) - na tentativa de revelar as relações de

\footnotetext{
${ }^{10}$ Disponível em: https://bit.ly/3fyrwD0. Acesso em: 30 de março de 2021.
} 
poder, ideologia e moralidades presentes em seus discursos. Desta forma, observamos que a (i)rracionalidade que sustenta o modus operandi da extrema-direita brasileira é dada por um regime de verdade que mobiliza o ressentimento e o ódio decorrentes do "poder masculino branco afrontado" para a articulação discursiva do neoliberalismo-neoconservadorismo ao negacionismo histórico e ao anticientificismo.

Ao circular a desconfiança em relação aos meios de comunicação tradicionais e dispensar mediações - imprensa, políticos, intelectuais, professores e experts em temas que mobilizam a opinião - Bolsonaro se apropria estrategicamente das tecnologias da comunicação para falar diretamente com os seus apoiadores, criando um ambiente ideologicamente homogêneo que contribui para o fortalecimento da sua credibilidade e favorece a circulação de mensagens que confirmam crenças e valores pré-existentes. Segundo Cook, McPherson e Smith-Lovin (2001), a homofilia - literalmente, "amor aos iguais” - é caracterizada como a tendência das pessoas de atração aos seus homônimos em relação a atributos como idade, sexo, crenças, educação e classe social. 0 termo foi cunhado em 1924 pelo psicanalista alemão Karl-Günther Heimsoth e, desde então, tem sido amplamente utilizado pela sociologia e outros campos, assim como nas análises de redes sociais de Internet.

São nestes espaços digitais constituídos por cidadão ressentidos com o sistema político que Bolsonaro estrategicamente constrói e comunica as suas verdades diretamente a uma "audiência midiática homofílica” (DVIR-GVIRSMAN, 2017) vinculada pela identificação com o líder e comprometida em defender as suais ideias. A atração ao "mito" está relacionada a uma necessidade de consistência de si (manter, distinguir e reforçar estilos de vida) que tende a polarizar as identidades políticas por meio de uma espiral de reforço. Ao longo do tempo, níveis mais altos de homofilia tendem a aumentar a acessibilidade do self-político dos indivíduos, o extremismo ideológico e a intolerância política.

Bolsonaro ignora que não é mais um candidato à presidência e a sua página oficial no Facebook não é mais um site de mídia partidário. Com a publicação do Decreto ${ }^{\circ}$ $9671 / 2019$, os perfis pessoais de Bolsonaro ganharam força de Oficiais, dando, inclusive, poder à Secretaria Especial de Comunicação Social da Secretaria de Governo da Presidência da República para administrar as suas contas. De acordo com o Decreto, Bolsonaro não estaria postando ataques à imprensa, à educação e às esferas independentes de poder na conta pessoal de um cidadão comum, mas nas "contas institucionais da Presidência da República em mídias sociais". 
Segundo recentes levantamentos do Datafolha (FARIA, 2019), publicados em julho de 2019, cerca de um terço dos brasileiros tem opinião similar à do presidente em aspectos como o golpe de 1964, demarcação de terras indígenas, política ambiental, posse de armas e a prioridade nas relações com os Estados Unidos. Também representam um terço da população os que, segundo a pesquisa, avaliam o governo Bolsonaro como ótimo ou bom (são 33\% com essa percepção, outros $31 \%$ consideram o governo regular e $33 \%$, ruim ou péssimo). A partir da leitura crítica aos enunciados postados pelo presidente em sua página no Facebook, compreendemos que o bolsonarismo não está interessado em construir pontes e buscar consenso entre a maioria da nação, mas em fragmentar o país em diversas minorias cujas experiências e crenças pessoais colidem entre si. A construção de sua verdade é feita justamente a partir da polarização, do conflito, da fúria dos seus adversários e, fundamentalmente, pela atualização do ressentimento do um terço da população - supostamente destituída do seu direito nato de supremacia econômica, política e cultural - em reações de hostilidade aos modos de existência e subjetividades tidos como inferiores e dissidentes.

\section{Referências bibliográficas}

ALEXANDER, J. Vociferando Contra o Iluminismo: a Ideologia de Steve Bannon. In: Sociologia \& Antropologia, 8 (3), 1009-1023. 2018.

BAKHTIN, Mikhail. Os Gêneros do Discurso - Estética da Criação Verbal. São Paulo: Martins Fontes, 1992.

BROWN, W. Neoliberalism's Frankenstein: Authoritarian Freedom in Twenty-First Century “Democracies”. In: Critical Times, 1 (1), 60-79, 2018.

CASTELLS, M. O Poder da Identidade. SP: Paz \& Terra, 2010.

COOK, J.; MCPHERSON, M.; SMITH-LOVIN, L. Birds of a Feather: Homophily in Social Networks. In: Annual Review of Sociology. vol. 27, p. 415-444, agosto de 2001.

DVIR-GVIRSMAN, S. Media Audience Homophily: Partisan Websites, Audience Identity and Polarization Processes. In: New Media \& Society. I-20, 2016.

FAIRCLOUGH, N. Language and power. London: Longman, 1989.

FARIA, F. Cerca de $1 / 3$ Pensa como Bolsonaro em Temas de Frases Agressivas, Indicam Pesquisas. In: Folha de São Paulo, 05 de agosto de 2019.

FASSIN, Éric em entrevista à PELÚCIO, Larissa e PAZ, Diego. “A democracia sexual no coração da democracia": a centralidade do gênero para a leitura do presente. IN: Interface, v. 23, 2019a. 
Brasil: o laboratório interseccional do neoliberalismo. In: Revista Cult, 22 de outubro de 2019b.

FOUCAULT, M. Segurança, Território, População. SP: Martins Fontes, [1977-1978] 2008a. . Nascimento da Biopolítica. SP: Martins Fontes, [1978-1979] $2008 \mathrm{~b}$.

HUNTER, J. Culture Wars. The Struggle to Define America. NY: BasicBooks, 1991.

KEYES, R. A Era da Pós-verdade: Desonestidade e Enganação na Vida Contemporânea. RJ, Editora Vozes, 2018.

KIMMEL, M. Angry White Men: American Masculinity at the End of an Era. NY: Nation Books, 2013.

MORETTO, Márcio; ORTELLADO, Pablo. Guerra de Narrativas: a Batalha do Impeachment no Facebook. In: El Pais, 17 de abril de 2016. Disponível em: https://goo.gl/GDLMjA. Acesso em: 04 de agosto de 2018.

Mapping Brazil's Political Polarization Online. In: The Conversation, 03 de agosto de 2018. Disponível em: https://goo.gl/SL5XDk. Acesso em: 04 de agosto de 2018.

OLIVEIRA, R. P. O Negacionismo Científico Olavista: a Radicalização de um Certo Regime Epistemológico. In: KLEM, B.; PEREIRA, M.; ARAUJO, V. Do Fake ao Fato: (Des)atualizando Bolsonaro. Vitória: Milfontes, 2020.

ROSE, N. Inventing Our Selves: Psychology, Power, and Personhood. Cambridge University, 1998.

ROTHBARD, Murray. O Grande Inimigo da Atualidade - e Como Lutar Contra Ele. In: Mises Brasil, 31 de dezembro de 2015. Disponível em: https://goo.gl/RH9kYA. Acesso em: 08 de dez. de 2018.

SALGADO, S. Online Media Impact on Politics. Views on Post-Truth Politics and Postpostmodernism. International Journal of Media \& Cultural Politics, Volume 14 Number 3. September 2018. pp 317-331.

WODAK, Ruth. What CDA is About - a Summary of Its History, Important Concepts and Its Developments. In: MEYER, Michael; WODAK, Ruth (Org.). Methods of Critical Discourse Analysis: Introducing Qualitative Methods. Londres, Thousand Oaks, New Delhi: Sage Publications, 2001. 